\title{
INDUCED INSULIN RESISTANCE IN THE RABBIT ${ }^{1}$
}

\author{
BY FRANCIS C. LOWELL AND WILLIAM FRANKLIN \\ (From the Evans Memorial and Massachusetts Memorial Hospitals and the Department of \\ Medicine, Boston University School of Medicine, Boston)
}

(Received for publication July 27,1948 )

A high degree of resistance to insulin occasionally develops in patients receiving repeated injections of insulin. This occurs most frequently in patients with diabetes, but non-diabetic individuals receiving insulin shock therapy for psychiatric disorders may also develop insulin resistance unassociated with any other demonstrable disturbance in carbohydrate metabolism. An immune mechanism has been repeatedly suggested as one underlying cause, a view for which strong evidence was obtained in the study of a case of insulin resistance in this laboratory (1-3). Resistance developed during the administration of insulin at the end of three insulin-free periods of three to five months, suggesting an immune response to the injected insulin. Furthermore, the resistance appeared to be species-specific as indicated by absence of resistance to human insulin at a time when resistance to commercial (beef and pork) insulin was clearly present. These observations prompted the study reported herein.

\section{MATERIALS AND METHODS}

Twenty-four adult rabbits of various breeds were injected subcutaneously according to a schedule similar to that shown in Table I for the fifth animal in the series. The injection mixture was made as follows: 1) Two parts of an insulin solution containing $250 \mathrm{u} / \mathrm{ml}$. with $0.5 \%$ phenol, 2) Three parts of Falba ${ }^{2}$ and 3) Five parts of mineral oil containing $5 \mathrm{mg}$. dry, heat-killed $M$. butyricum per $\mathrm{ml}^{3}$ The insulin and Falba were thoroughly mixed with an electric stirrer and the mineral oil containing the acid-fast organisms was then added and likewise thoroughly mixed. Each milliliter of the final mixture contained $50 \mathrm{u}$ of insulin. Preliminary tests showed that the injection of more than $50 u$ into rabbits often caused severe hypoglycemic symptoms or death. Masses of various sizes and consistencies appeared at the injected sites and in some instances drained

1 This work was supported by a grant-in-aid from the U. S. Public Health Service.

2 Pfaltz and Bauer, Inc., Empire State Building, New York.

3 The authors are indebted to Dr. Jules Freund for advice and for supplying the strain of $M$. butyricum. purulent material. Before receiving the insulin-adjuvant mixture, some animals were injected intravenously in the fasting state with $0.1 \mathrm{u}$ crystalline insulin per kilogram in order to test the responsiveness to insulin. In every instance in which this was done, a definite but brief fall in blood sugar occurred. Blood sugar determinations using $0.2 \mathrm{ml}$. of blood were done with the micro-method described by Nelson (4), using the Folin method of precipitation (5). Blood was obtained from the ear veins with a No. 26 hypodermic needle and a dry tuberculin syringe. The animals were not tied down or otherwise forcibly held. Struggling could be avoided in most instances by infiltrating the area around the vein with novocaine. Insulin tolerance tests with $0.1 \mathrm{u} / \mathrm{kg}$. were repeated at intervals of five to ten weeks and further injections of the insulin-adjuvant mixture were given according to a schedule similar to that shown in Table I. The human insulin used in these experiments was prepared in the summer of 1947 from human pancreas obtained from two to 27 hours post-mortem with a method modified after Somogyi (6). The material was sterilized by passage through a Seitz filter and phenol was added to make a final concentration of $0.5 \%$. Assay in mice and rabbits indicated that each milliliter contained $24 \pm$ $2 \mathrm{u} / \mathrm{ml}$. The details of the preparation and assay of the human insulin are given elsewhere (7).

\section{RESULTS}

Of the 24 animals injected with the insulinadjuvant mixture, four became insulin-resistant. One of these animals, the first to become resistant, has been studied in detail and forms the subject of this report. One of the other resistant animals died of causes apparently unrelated to the experimental procedure, and the remaining two appear to be in good health. Of the 20 rabbits which failed to become resistant, nine died within six months of starting immunization. Ten animals have received injections of the.adjuvant mixture for eight months or more without becoming resistant.

The fifth rabbit in our series developed clearcut resistance to insulin three months after injections of the insulin-adjuvant mixture were begun. All the procedures carried out in this animal are shown in Table I. The number of tests performed was limited by the tendency of the ear 
veins to become thrombosed after continued use, be due to undetected errors in technic but the though care was taken to avoid this. Some of data clearly indicate the development of a high the insulin tolerance tests shown in Table I are degree of resistance to crystalline insulin. In this irregular, as for example those done on 10/15/47, animal, a dose of $0.1 \mathrm{u} / \mathrm{kg}$. crystalline insulin $11 / 4 / 47$ and $11 / 19 / 47$. These irregularities may intravenously had caused a fall of $20 \mathrm{mg} . / 100 \mathrm{ml}$.

TABLE I

Procedures done in the insulin-resistant rabbit

\begin{tabular}{|c|c|c|c|c|c|c|c|c|c|c|}
\hline \multirow{3}{*}{ Date } & \multirow{3}{*}{ Weight } & \multirow{3}{*}{ Procedure } & \multicolumn{8}{|c|}{ Results of insulin tolerance tests. Blood glucose $\mathrm{mg} .1100 \mathrm{ml}$. } \\
\hline & & & \multirow{2}{*}{ FBS } & \multicolumn{7}{|c|}{ Minutes after injection of insulin } \\
\hline & & & & 15 & 30 & 45 & 60 & 90 & 120 & 180 \\
\hline $2 / 5 / 47$ & $\begin{array}{l}k g . \\
2.3\end{array}$ & Crystalline insulin $0.1 \mathrm{u} / \mathrm{kg} . \mathrm{I} . \mathrm{V}$. & 118 & 100 & 98 & & 113 & & 113 & \\
\hline $\begin{array}{l}5 / 29 / 47- \\
6 / 30 / 47\end{array}$ & & $\begin{array}{l}\text { Four subcutaneous injections of adjuvant } \\
\text { mixture containing } 25 \mathrm{u} \text { crystalline insulin } \\
\text { in } 0.5 \mathrm{ml} \text {. }\end{array}$ & & & & & & & & \\
\hline $7 / 9 / 47$ & 3.15 & Crystalline insulin $0.1 \mathrm{u} / \mathrm{kg} . \mathrm{I} . \mathrm{V}$. & 93 & 79 & 76 & & 89 & & 85 & \\
\hline $7 / 30 / 47$ & 3.4 & $\begin{array}{l}1 \mathrm{ml} \text {. adjuvant mixture subcutaneously } \\
\text { containing } 50 \mathrm{u} \text { crystalline insulin }\end{array}$ & & & & & & & & \\
\hline $9 / 17 / 47$ & 3.6 & Crystalline insulin $0.1 \mathrm{u} / \mathrm{kg} . \mathrm{I} . \mathrm{V}$. & 114 & 108 & 117 & & 129 & & 95 & 101 \\
\hline $9 / 19 / 47$ & 3.6 & Crystalline insulin $0.1 \mathrm{u} / \mathrm{kg} . \mathrm{I} . \mathrm{V}$. & 76 & 85 & 76 & & 89 & & & 97 \\
\hline $9 / 23 / 47$ & 3.6 & Crystalline insulin $0.4 \mathrm{u} / \mathrm{kg} . \mathrm{I} . \mathrm{V}$. & 108 & 97 & 87 & & 103 & & 101 & 101 \\
\hline $10 / 8 / 47$ & & $\begin{array}{l}1 \mathrm{ml} \text {. adjuvant mixture subcutaneously } \\
\text { containing } 50 \mathrm{u} \text { crystalline insulin }\end{array}$ & & & & & & & & \\
\hline $10 / 15 / 47$ & & Crystalline insulin $0.8 \mathrm{u} / \mathrm{kg} . \mathrm{I} . \mathrm{V}$. & 80 & 109 & 109 & & 85 & & 105 & 93 \\
\hline $10 / 17 / 47$ & & Crystalline insulin $1.6 \mathrm{u} / \mathrm{kg} . \mathrm{I} . \mathrm{V}$. & $105^{*}$ & & 117 & & 117 & & & \\
\hline $10 / 20 / 47$ & & Crystalline insulin $4.4 \mathrm{u} / \mathrm{kg} . \mathrm{I} . \mathrm{V}$. & $91^{*}$ & & 64 & & 76 & & 109 & \\
\hline $10 / 24 / 47$ & & $\begin{array}{l}1 \mathrm{ml} \text {. adjuvant mixture subcutaneously } \\
\text { containing } 50 \mathrm{u} \text { crystalline insulin }\end{array}$ & & & & & & & & \\
\hline $10 / 29 / 47$ & & Human insulin $0.32 \mathrm{u} / \mathrm{kg} . \mathrm{I} . \mathrm{V}$. & 81 & & 42 & & 84 & 87 & 97 & \\
\hline $10 / 31 / 47$ & & Human insulin $0.32 \mathrm{u} / \mathrm{kg} . \mathrm{I} . \mathrm{V}$. & 90 & 36 & 60 & 74 & 85 & 90 & 97 & 109 \\
\hline $11 / 4 / 47$ & & Crystalline insulin $2.5 \mathrm{u} / \mathrm{kg} . \mathrm{I} . \mathrm{V}$. & 79 & 108 & 71 & 63 & 100 & 103 & 104 & 111 \\
\hline $11 / 19 / 47$ & & Crystalline insulin $0.32 \mathrm{u} / \mathrm{kg} . \mathrm{I} . \mathrm{V}$. & 144 & 99 & 101 & 104 & 105 & 106 & 103 & 104 \\
\hline $1 / 6 / 48$ & 4.08 & Crystalline insulin $0.5 \mathrm{u} / \mathrm{kg} . \mathrm{I} . \mathrm{V}$. & 96 & 94 & 84 & 84 & 85 & 94 & 94 & \\
\hline $1 / 8 / 48$ & 4.08 & $\begin{array}{l}\text { Cysteine-inactivated insulin } 15 \mathrm{u} / \mathrm{kg} . \mathrm{I} . \mathrm{V} \text {. } \\
\text { followed in } 20 \text { minutes by crystalline insu- } \\
\text { lin } 0.5 \mathrm{u} / \mathrm{kg} . \mathrm{I} . \mathrm{V} \text {. The inactivated insulin } \\
\text { caused a rise in blood sugar from } 87 \mathrm{mg} . / \\
100 \mathrm{ml} \text {. to the fasting level shown. }\end{array}$ & 104 & 59 & 54 & 67 & 66 & 72 & 80 & \\
\hline $1 / 12 / 48$ & 4.08 & $\begin{array}{l}\text { Cysteine-inactivated insulin } 15 \mathrm{u} / \mathrm{kg} . \mathrm{I} . \mathrm{V} \text {. } \\
\text { This caused a rise in blood sugar from } \\
80 \mathrm{mg} . / 100 \mathrm{ml} \text {. to the fasting level shown. } \\
\text { No active insulin given. }\end{array}$ & 132 & 111 & 100 & 101 & 99 & & 91 & \\
\hline $2 / 26 / 48$ & 3.96 & Crystalline insulin $0.5 \mathrm{u} / \mathrm{kg}$. & 88 & 92 & 95 & 97 & 98 & 102 & 82 & \\
\hline $3 / 19 / 48$ & & Crystalline insulin $2.5 \mathrm{u} / \mathrm{kg}$ & 80 & & 93 & & 92 & 92 & & \\
\hline
\end{tabular}

* Animal not fasted. 


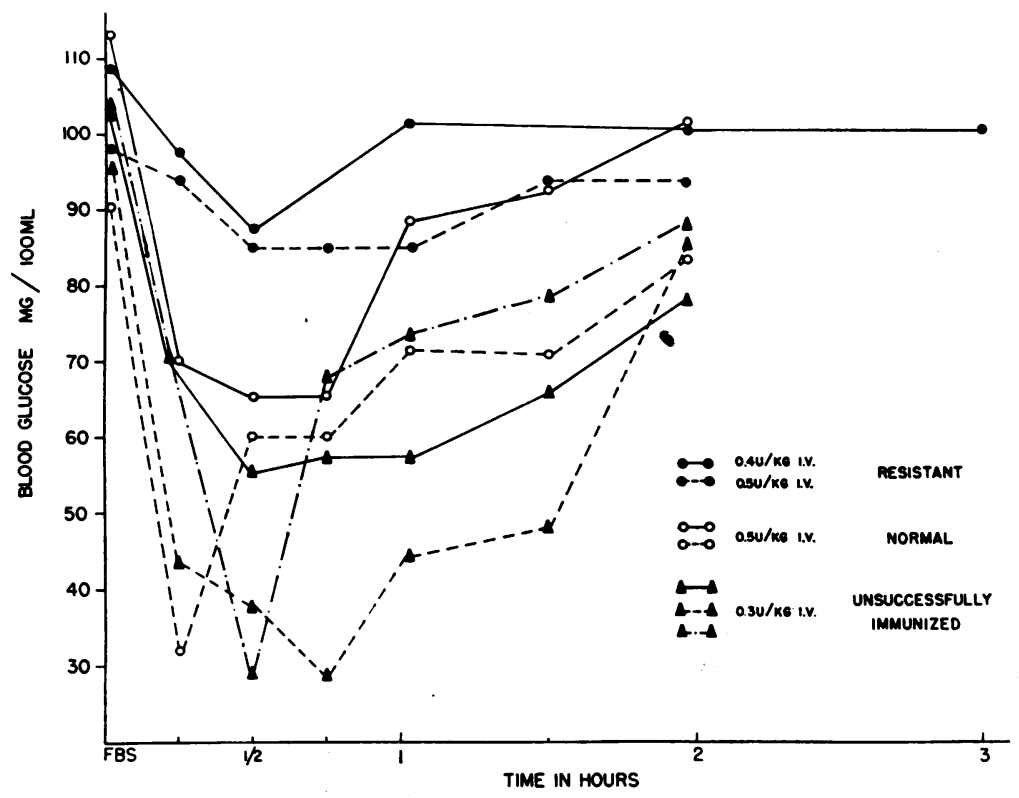

FIG. 1

The dates on which the insulin tolerance tests in the resistant rabbit were done were as follows:

$0.4 \mathrm{u} / \mathrm{kg}$. I. V. 9/23/47. This test is also shown in Figure 3.

$0.5 \mathrm{u} / \mathrm{kg}$. I. V. 1/6/48. This test is also shown in Figures 3 and 5 .

in the blood sugar before any injections of the adjuvant mixture were given and a similar fall followed the same dose of insulin six weeks after these injections were begun. After three or more months, four or five times this dose $(0.4 \mathrm{u} / \mathrm{kg}$. and $0.5 \mathrm{u} / \mathrm{kg}$.) given intravenously caused a fall of $21 \mathrm{mg} . / 100 \mathrm{ml}$. or less as shown in the two upper curves of Figure 1. The blood sugars of two normal rabbits receiving $0.5 \mathrm{u} / \mathrm{kg}$. fell 40 $\mathrm{mg} . / 100 \mathrm{ml}$. and $60 \mathrm{mg} . / 100 \mathrm{ml}$., respectively, and in two other animals, which received the adjuvant mixture but failed to become resistant, marked falls in blood sugar followed the injection of $0.3 \mathrm{u} / \mathrm{kg}$. Further tests done in the resistant animal are shown in Figure 2 where it may be seen that a large dose of insulin $(4.4 \mathrm{u} / \mathrm{kg}$.) was required to produce a moderate fall in blood sugar. Two of the tests shown in Figure 2 were done without fasting in order to decrease the risk of killing the animal in hypoglycemic shock, a precaution which was probably unnecessary. The curve obtained in the fasting state with $2.5 \mathrm{u} / \mathrm{kg}$. was done at a later date than the others and we
INTRAVENOUS TOLERANCE TESTS WITH LARGE DOSES OF COMMERCIAL INSULIN AFTER DEVELOPMENT OF RESISTANCE

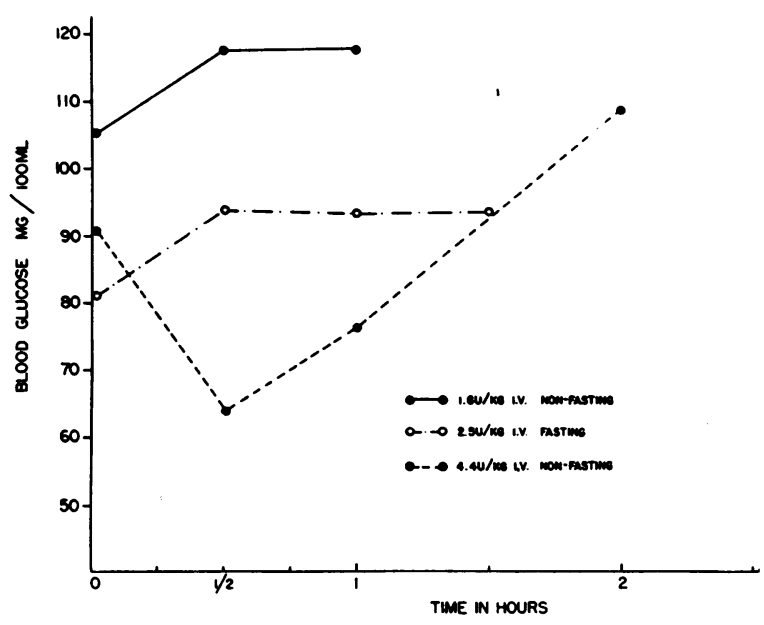

FIG. 2

The dates on which the insulin tolerance tests were done were as follows:

$1.6 \mathrm{u} / \mathrm{kg}$. I. V. non-fasting $10 / 17 / 47$.

$2.5 \mathrm{u} / \mathrm{kg}$. I. V. fasting $3 / 19 / 48$.

$4.4 \mathrm{u} / \mathrm{kg}$. I. V. non-fasting $10 / 20 / 47$. 
have reason to believe, on the basis of protection studies in mice (8) with the animal's serum, that a higher degree of resistance was present at this time. These studies will be reported later.

The condition of the site at which the adjuvant mixture was injected did not appear to influence the animals' response to insulin as judged by the normal insulin tolerance curves obtained in animals with fluctuant masses or draining sinuses. Furthermore, only one of the four animals that became resistant developed any significant inflammation at the injected site, and even in this subject resistance to insulin was clearly demonstrable when the inflammation had subsided.

In none of the tolerance tests done in this animal were there any symptoms suggesting a hypoglycemic reaction or any allergic manifestations such as scratching, dyspnea, or collapse. The endermal injection of $0.02 \mathrm{ml}$. of crystalline insulin in a concentration of $4 \mathrm{u} / \mathrm{ml}$. on two occasions caused no immediate or delayed local reaction.
The repeated finding of a normal fasting blood sugar indicated that the animal had no resistance to his own insulin. Furthermore, the animal appeared to be in good health and gained weight steadily. An intravenous glucose tolerance curve with $0.5 \mathrm{gm}$. glucose $/ \mathrm{kg}$. gave the following result suggesting normal carbohydrate metabolism. FBS 90 mg./100 ml.; 30 minutes, 116 mg./100 $\mathrm{ml}$; one hour, $88 \mathrm{mg} . / 100 \mathrm{ml}$; two hours, 88 mg. $/ 100 \mathrm{ml}$; three hours, $88 \mathrm{mg} . / 100 \mathrm{ml}$. In view of the presence of resistance to commercial insulin, these results indicated the presence of a species-specific immunity to beef and pork, but not to rabbit insulin.

Further evidence for the species specificity of the resistance was obtained in tests with human insulin. Curves are shown in Figure 3 where approximately $0.3 \mathrm{u} / \mathrm{kg}$. of human insulin caused falls in blood sugar of $39 \mathrm{mg} . / 100 \mathrm{ml}$. and 54 $\mathrm{mg} . / 100 \mathrm{ml}$., results which were similar to those obtained in normal animals receiving either human or crystalline insulin in this dosage. As

COMPARISON OF RESPONSE TO COMMERCIAL AND HUMAN INSULIN

AFTER IMMUNIZATION

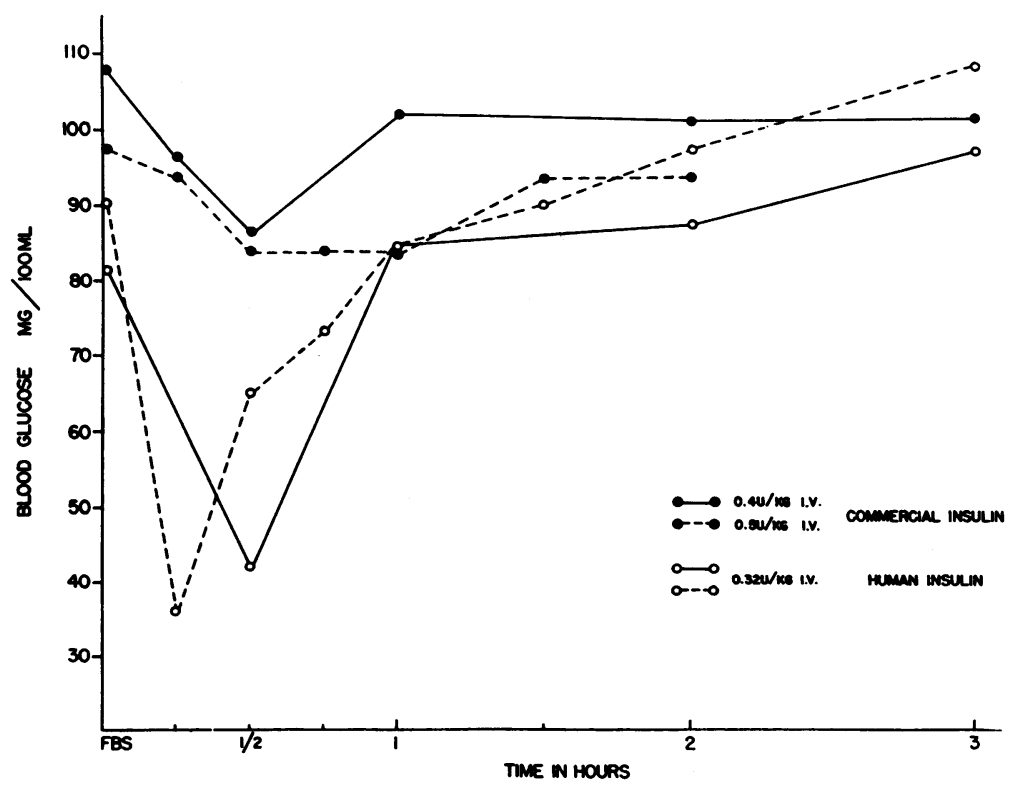

FIG. 3

The dates on which the insulin tolerance tests were done were as follows :

$0.4 \mathrm{u} / \mathrm{kg}$. l. V. commercial insulin 9/23/47.

$0.5 \mathrm{u} / \mathrm{kg}$. I. V. commercial insulin $1 / 6 / 48$.

$0.32 \mathrm{u} / \mathrm{kg}$. I. V. human insulin (solid line) 10/29/47.

$0.32 \mathrm{u} / \mathrm{kg}$. I. V. human insulin (dotted line) 10/31/47. 
TESTS WTH ACTIVE INSULIN,CYSTEINE-INACTIVATED NSULIN AND THE

COMBINATION OF THE TWO IN NORMAL RABBITS

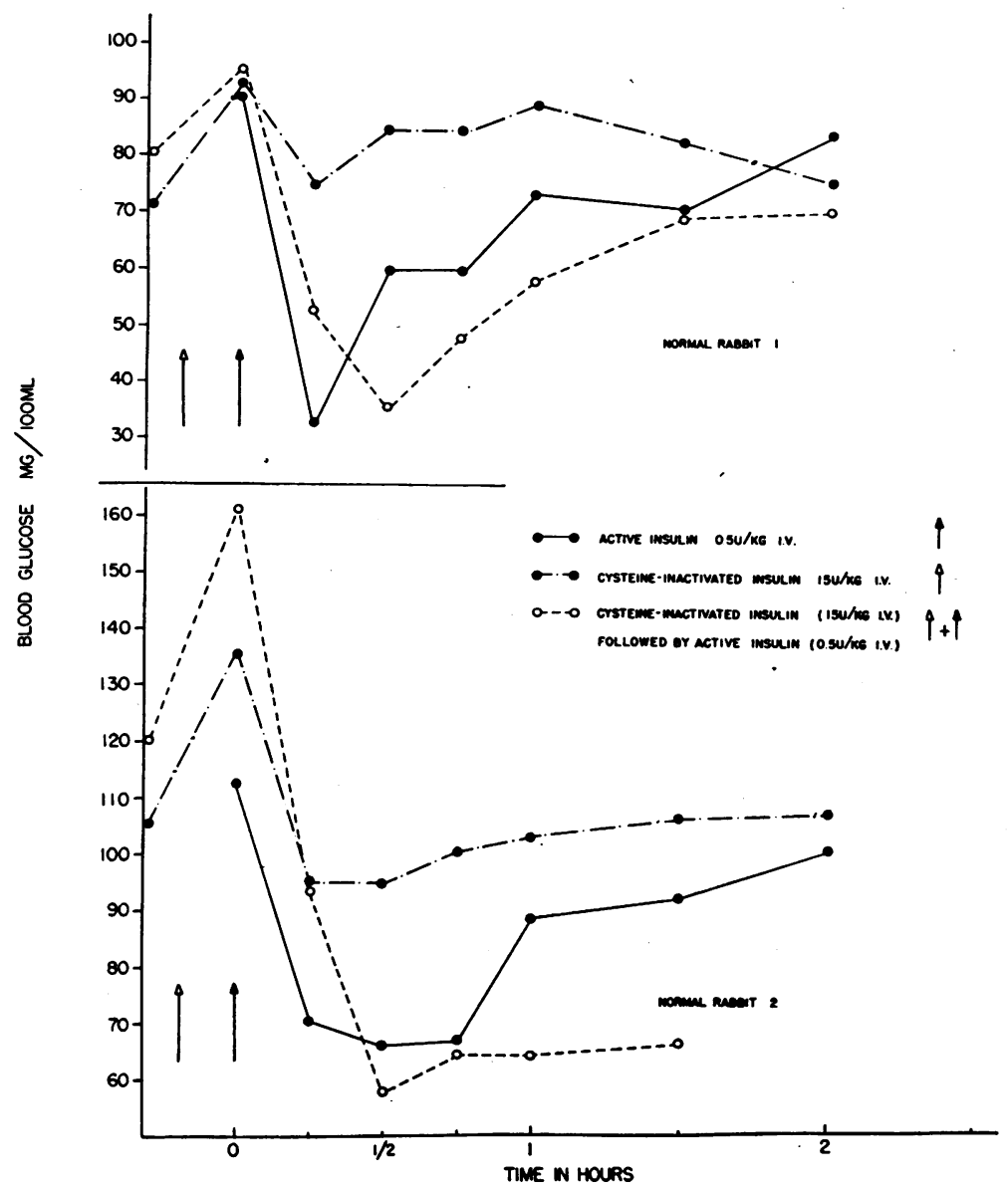

FIG. 4

described above, much smaller falls in blood sugar followed the injection of $0.4 \mathrm{u} / \mathrm{kg}$. and $0.5 \mathrm{u} / \mathrm{kg}$. of commercial insulin. The tests with human insulin were done in the period between the two tests with commercial insulin and therefore it is unlikely that the responsiveness to human insulin was due merely to the loss of a resistance which was not species-specific.

A final experiment was based on the assumption that the resistant animal's antibody was directed against antigenic determinants on the insulin molecule which were distinct from the group or groups to which the hormone owes its specific effect on carbohydrate metabolism. Accordingly, if the insulin molecule were shorn of its active group, antibody might still combine with it and the injection of a large amount of such insulin into the resistant animal, by combining with the animal's antibody, might then bring about temporary susceptibility to the action of a relatively small dose of active insulin.

To this end, $400 \mathrm{u}$ of crystalline insulin were inactivated under reduced oxygen tension with $167 \mathrm{mg}$. cysteine $\mathrm{HCl}$ in the presence of sufficient $\mathrm{NaOH}$ to bring the $\mathrm{pH}$ to approximately 7.0 (9). After the addition of phenol to make a final concentration of $0.5 \%$, the solution contained the equivalent of $27 \mathrm{u} / \mathrm{ml}$. During the procedure and upon exposure to room air the cysteine in this mixture slowly became oxidized to cystine forming a precipitate which was resuspended each time the solution was used. When tested in fasting mice, $0.5 \mathrm{ml}$. of a $1: 5$ dilution failed to induce any symptoms at $35^{\circ} \mathrm{C}$., indicating that 
NFLUENCE OF CYSTENE-INACTIVATED INSULIN ON THE SUSCEPTIBILITY OF THE INSULIN-RESISTANT RABBIT TO ACTIVE INSULIN

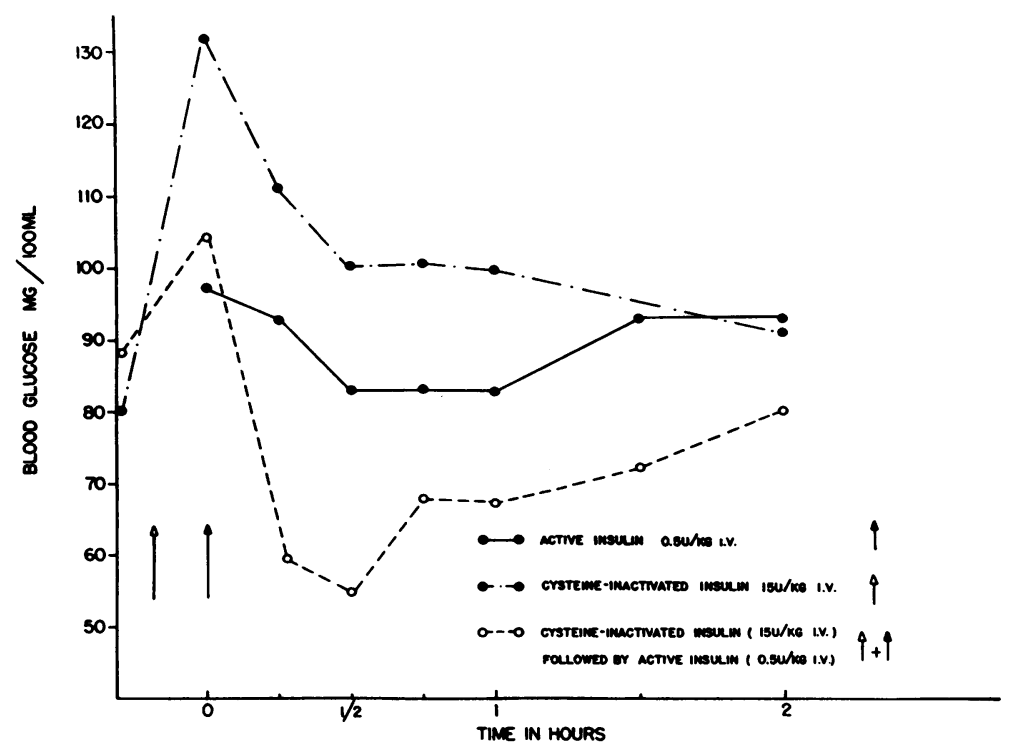

FIG. 5

The dates on which the insulin tolerance tests were done were as follows :

Active insulin $0.5 \mathrm{u} / \mathrm{kg}$. I. V. 1/6/48.

Cysteine-inactivated insulin $15 \mathrm{u} / \mathrm{kg}$. I. V. $1 / 12 / 48$.

Cysteine-inactivated insulin followed by active insulin $1 / 8 / 48$.

the insulin had been at least $99 \%$ inactivated.

The experiments with cysteine-inactivated insulin are shown in Figures 4 and 5. Each experiment consisted of three blood sugar curves done with cysteine-inactivated insulin alone, active insulin alone and cysteine-inactivated insulin followed in 20 minutes by active insulin. All injections were made intravenously. In each instance, the injection of the inactivated insulin caused a temporary rise in blood sugar which may have been due entirely or in part to the cysteine present. In the normal animals, the hypoglycemic effect of active insulin given after cysteine-inactivated insulin was like that of active insulin alone. A strikingly similar result was obtained in the resistant animal though active insulin alone caused only a slight fall in blood sugar. Thus, two agents-one of which lacked blood sugar lowering activity and indeed tended to raise the blood sugar, and the other having only a feeble blood sugar lowering effect in this animal-combined to produce a pronounced fall in blood sugar. These results indicate that the inactivated hormone combined with the animal's antibody, leaving the active insulin free to lower the blood sugar.

\section{DISCUSSION}

The experimental production of a speciesspecific resistance to insulin in the rabbit on an immunological basis is evidence for the antigenicity of insulin and gives further support to the view that some instances of resistance to insulin in man have an immune basis. The element of species specificity explains the coexistence of resistance to exogenous insulin on the one hand and undisturbed utilization of endogenous insulin on the other. This appears to be the case in the resistant rabbit reported herein as well as in certain instances of insulin resistance which have been observed among non-diabetic patients receiving insulin-shock therapy.

It is difficult on the basis of our observations to arrive at a conclusion regarding the antigenic- 
ity of insulin in the adjuvant mixture used, owing to the high mortality of our animals. It can be safely stated, however, that with the method used only a small proportion of animals will develop resistance within three months of the time immunization is begun. The possibility remains, however, that all animals might become resistant if immunization were sufficiently prolonged. The failure of other workers to produce unequivocal resistance to insulin on an immunological basis in experimental animals may have been due to the omission of adjuvants and perhaps the use of an insufficiently sensitive test for the detection of resistance. In their paper describing the successful production of complement-fixing antibodies to insulin in rabbits receiving large intravenous and subcutaneous injections of insulin, Wasserman et al. state (10) that no resistance to insulin developed. However, the method used in attempting to show resistance was not described. The relationship between complement-fixing antibodies, precipitins and susceptibility to anaphylaxis on the one hand and resistance to insulin on the other will require further investigation.

Earlier studies in this laboratory $(1,2)$ as well as those reported herein are in conflict with the claim made by Wasserman and Mirsky (11) that insulins from various animal sources are immunologically identical. Indeed the observations in our insulin-resistant animal can hardly be explained other than by assuming different immunologic specificities for rabbit and human insulins on the one hand and beef and pork on the other. There is one possible, but unlikely, explanation for the results obtained by us, which retains the concept of the immunologic identity of all insulins. The assumption can be made that the modern method for the commercial extraction and purification of insulin alters the molecule so as to confer upon it a new immunologic specificity. According to this hypothesis, the resistant animal's antibody is directed against insulin modified by the method currently used in the preparation of commercial insulin and would fail to combine with native insulin (endogenous rabbit insulin) or human insulin extracted by the older method used by us.

The experiment with cysteine-inactivated insulin suggests that the antigenic specificity of the insulin molecule is little altered by inactivation, a result which is in accord with conclusions reached by Wasserman et al. (10). This experiment also indicates that the total available antibody in the resistant animal was not in excess of an amount which would neutralize $60 u$ of insulin $(15 \mathrm{u} / \mathrm{kg}$.). The estimated degree of resistance in this animal may therefore be less than that seen in some instances of human resistance to insulin which may require more than $5000 \mathrm{u}$ in 24 hours $(70 \mathrm{u} / \mathrm{kg}$. $)$. However, regeneration of antibody during the 24-hour period may be one factor contributing to the large insulin requirement in such cases.

\section{SUMMARY}

Resistance to the hypoglycemic action of commercial crystalline (beef and pork) insulin was induced in the rabbit by the repeated subcutaneous injection of crystalline insulin incorporated in an adjuvant mixture. The resistance to insulin was species-specific, as indicated by both the animal's failure to develop hyperglycemia and the response to human insulin, and appeared to be due to the development of an antibody for insulin. Evidence is presented which indicates that insulin treated with cysteine so as to destroy its hypoglycemic activity retains its capacity to combine with antibody.

We take pleasure in expressing our indebtedness to Miss Jean Buckley for technical assistance.

\section{BIBLIOGRAPHY}

1. Lowell, F. C., Evidence for the existence of two antibodies for crystalline insulin. Proc. Soc. Exper. Biol. \& Med., 1942, 50, 167.

2. Lowell, F. C., Immunologic studies in insulin resistance. I. Report of a case exhibiting variations in resistance and allergy to insulin. $\mathrm{J}$. Clin. Invest., 1944, 23, 225.

3. Lowell, F. C., Immunologic studies in insulin resistance. II. The presence of a neutralizing factor in the blood exhibiting some characteristics of an antibody. J. Clin. Invest., 1944, 23, 233.

4. Nelson, N., A photometric adaptation of the Somogyi method for the determination of glucose. J. Biol. Chem., 1944, 153, 375.

5. Folin, O., Micromethod for the determination of blood sugar. New England J. Med., 1932, 206, 727.

6. Somogyi, M., Doisy, E. A., and Shaffer, P. A., On the preparation of insulin. J. Biol. Chem., 1924, $60,31$. 
7. Franklin, W., and Lowell, F. C., On the preparation of human insulin for experimental use. To be - published in J. Clin. Endocrin.

8. Lowell, F. C., Immunologic studies in insulin resistance. III. Measurement of an insulin antagonist in the serum of an insulin-resistant patient by the blood sugar curve method in mice. J. Clin. Invest., 1947, 26, 57.

9. du Vigneaud, V., Fitch, A., Pekarek, E., and Lock- wöod, W. W., The inactivation of crystalline insulin by cysiteine and glutathione. J. Biol. Chem., 1931, 94, 233.

10. Wasserman, P., Broh-Kahn, R. H., and Mirsky, I. A., The antigenic property of insulin. J. Immunol., 1940, 38, 213.

11. Wasserman, P., and Mirsky, I. A., Immunological identity of insulin from various species. Endocrinology, 1942, 31, 115 . 